\title{
Pre-Service Math Teachers' Opinions about Dynamic Geometry Softwares and Their Expectations from Them
}

\author{
Hakan Sandır ${ }^{\mathrm{a}}$ and Serdar Aztekin ${ }^{\mathrm{a}}$
}

${ }^{a}$ Gazi University, TURKEY

\section{ARTICLE HISTORY \\ Received 15 September 2015 Revised 10 November 2015 \\ Accepted 22 February 2016 \\ KEYWORDS \\ Dynamic Geometry Software, Pre-service Teachers' \\ Expectations, Cabri II Plus, the Geometer's Sketchpad, GeoGebra}

\begin{abstract}
This study was designed to determine the pre-service teachers' opinions about three dynamic geometry software (Cabri II Plus, the Geometer's Sketchpad, GeoGebra) and influences of gender and academic achievement to these opinions. The researchers also investigated the most important properties that the pre-service teachers expect from a dynamic geometry software. The study was conducted in the 2011-2012 academic year with 64 prospective teachers who had taken a course about math education software during a year in the university. Results revealed that pre-service teachers found Geometers' Sketchpad more effective than others in the positive development of the students attitudes and in teaching high level geometry. However, they think that GeoGebra is easier than Cabri II Plus to use and has wide area of use. According to the pre-service teachers; using a native language, screen clarity, a detailed user manual and the ease of use are the most important properties of a dynamic geometry software.
\end{abstract}

\section{Introduction}

Educators and teachers have often struggled with technology as a means of educational development. With this problem in mind, an increase in software development for teaching and learning of Geometry has lead to a growing number of dynamic geometry software products in education. Dynamic geometry softwares (DGS) have a variety of functions and purposes that cover a broad array of topic and provide the user a discovery-learning environment. Hull and Brovey (2004) state that DGS is a multi-faceted tool encompassing areas ranging from problem solving to geometric constructions and transformations etc.

In the past, there has been much research dedicated to studying the effect of DGS on students' progress along with their attitudes in geometry. Although they have shown mixed results; most of them emphasized that the use of DGS improved students' achievement, interest and participation in geometry (e.g., Bielefeld, 2002; Erbas \&Yenmez, 2011; Guven, 2012; Roberts \& Stephens, 1999). Many researchers 
conclude that effectively applying DGS as a learning tool is very important. The problem herein lies with finding a good software that not only conveys mathematical ideas but allows students to explore it (Isiksal \& Askar, 2005).

Ever since the mass adoption of computers in schools, DGS has been implemented in all levels ranging from elementary to collegiate in countries (Sträßer, 2002). Some 2D and 3D DGS are easily accessible, from the internet, and free without any limitation. Thus teachers should be implementing these softwares and bringing this technology into their classrooms. However, teachers struggle with choosing the appropriate software for their students.

\section{Cabri II Plus, the Geometer's Sketchpad and GeoGebra}

Cabri II Plus, the Geometer's Sketchpad and GeoGebra are used as a learning tool for small groups and individualized studies in classes ranging from elementary to collegiate. (Oldknow \& Tetlow, 2008; Hull \& Brovey, 2004).

The oldest version of Cabri II Plus (Cabri-Geometrie), which was the first of these dynamic geometry softwares, was created by the team from CNRS - "Centre National de la Recherche Scientifique" in 1985 (Petrovici et al., 2010). Today its new version Cabri II Plus is widely used software on computers as well as on Texas Instruments graphing calculators.

The Geometer's Sketchpad was developed as part of the Visual Geometry Project. It was developed in an open academic environment in which many teachers and other users experimented with early versions of the program and provided input to its design.

GeoGebra that is the latest and freely downloadable DGS is an interactive geometry, algebra, and calculus application, which has a holistic approach, providing visualization of Computer Algebra System (CAS). It can be used from simple constructions to the integration of functions (Hohenwarter \& Lavicza, 2007).

Teachers can provide $2 \mathrm{D}$ learning environments at schools by all of these software. In math lessons, computer based activities, tasks and pedagogical context are important factors which determine learning outcomes but they are not all. Also software design effects these outcomes. Mackrell (2011) concluded that particular design decisions were likely to facilitate the development of student understanding. There are many studies about software design decisions and comparisons made between them (Mackrell, 2011; Laborde, 2007; Butler, Jackiw, Laborde, Lagrange \& Yerushalmy, 2009). Although the similarities are much more than the differences, there are some differences in software design and syntax. Oldknow (2001) compared Cabri with GSP and stated that there is a fundamental difference in their syntax and applications. Initially GSP prompts the user to select the object before selecting the operation, whereas in Cabri these two are reversed. Mackrell (2011) used a categorization of the operations possible within a dynamic geometry software to determine how design decisions are made in certain DGS programs: Cabri II Plus, Cabri 3D, Cinderella, GeoGebra and Geometer's Sketchpad. She specifically looked at the "construction, dragging, and alternative spatial and semantic views of DGS with basic tasks such as finding the area of a circle". She noted differences between their design decisions and properties.

"In the Cabri softwares and GeoGebra, tools are organized into toolboxes on toolbars, while in Cinderella and GSP tools are in a combination of menus and toolbars, highlighting is used in all but Cabri II Plus, and is the most noticeable in 
GSP and least noticeable in GeoGebra; GSP and Cabri 3D give feedback messages by a graphic preview of the point, but Cabri II Plus does not" (for further details, see Mackrell (2011)).

The other issue is the ease of use which is affected by the number of tools and the complexity of the interface. The vast number of different capabilities were intimidating for not only the student but also the teacher. Both students and teacher would benefit from a more fluid and straightforward interface. In fact often these tools were distracting and rarely used. (Kittel, 2007, cited in Kortenkamp \& Dohrmann). In GSP and GeoGebra, the last constructed object is selected by default. Unlike the others, in Cabri II Plus, the object must be reselected, which leads to confusion on the part of the user. Mackrell (2011) stated that "User choice is the most flexible option, but the requirement to make a choice may confuse and distract."

\section{Teachers' Perceptions About Dynamic Geometry Software}

There are few studies that express the feeling and comfort levels of mathematics teacher on their usage of dynamic mathematics software and technology in their classrooms (For example; Daher, 2009; Stols \& Kriek, 2011). Daher (2009) examined the pre-service teachers' perceptions of solving mathematical problems with the help of applets. Other studies specifically looked at DGS and the role the educators ideologies play in its effectiveness. Stols \& Kriek (2011) studied the effects of teachers' feelings toward dynamic mathematics software and their overall usage of the software. They applied information, including teachers' attitudes, subjective norms and perceived behavioral control, to existing models that predict and explain human behavior. Their results showed that their initial feelings along with their level of technological savvy are the greatest predictors of whether or not the teachers use and intend to use the software. They introduced GeoGebra, Cabri and Geometer's Sketchpad to compare their usage with teachers' intention to use dynamic geometry software.

Investigating teachers' perceptions and opinions about education software is crucial for determining the borders of a good and an effective education software. This study aims to extend the literature related with the effectiveness of education software. It was designed to determine the pre-service teachers' opinions about three dynamic mathematics softwares (Cabri II Plus, the Geometer's Sketchpad, GeoGebra) and influences of gender and academic achievement to these opinions. It compares GeoGebra, Cabri, Geometer's Sketchpad according to the pre-service teachers' opinions. There are three main objectives for this study, namely: 1) to assess and to compare well-known softwares; Cabri II Plus, the Geometer's Sketchpad and GeoGebra, 2) to produce a criteria for analyzing and categorizing dynamic geometry softwares, 3) to provide a foundation for progressing educational softwares in accordance with the prospective teachers' expectations. DGS cannot be defined as simple dynamic representations of geometric shapes and symbols. It is influenced by the epistemology of the designer, cultural conventions and pedagogical considerations (Mackrell, 2011). The researchers think that the pre-service math teachers' educational considerations about DGS can make a contribution to the development of DGS and its' usage. 


\section{Methods and Procedures}

\section{Sample and Course}

This study was conducted in the 2011-2012 academic year with 64 pre-service teachers who had taken a course about mathematics education softwares during a year in the university which is located in Ankara, Turkey. They had learned to use 3 dynamic geometry softwares in the first semester. Then in the second semester they were assigned to the course about math education softwares involved workshops, sample activities and applications. They participated weekly in three hour lessons instructed by one of the authors of this paper and they were asked to prepare dynamic geometry software activities weekly. Researchers did everything they could to avoid manipulating participants about any software. The instructor of the course spared equal time to each software, and pre-service teachers were free to choose any kind of software while they were preparing an activity. They were given equal number of dynamic geometry software activities, with questions in each activity. The instructor provided extra guidance to the students in case they needed help during learning.

\section{Instruments}

In order to determine the opinions of the pre-service math teachers with respect to dynamic geometry softwares, "Dynamic Geometry Software Evaluation Scale (DGSES)" was developed by the researchers after overviewing the related literature. The DGSES was a likert-type five-point scale, ranging from 'strongly agree' to 'strongly disagree'. A pilot study of the scale was conducted with 90 pre-service teachers who learned to use 3 dynamic geometry softwares from different courses in the same university. There were 25 items in the scale but, after the pilot study and factor analysis, 6 of the items were eliminated. The Cronbach's alpha for pilot study was calculated as 0.81 for 25 items and 0.91 for 19 items. The DGSES (KMO: .84) has 19 items and four subscales: the impact of DGS on students' attitudes and lessons (6 items), high level geometry teaching ( 5 items), range and ease of use (5 items), teaching geometric shapes and concepts (3 items). DGSES was used as a data gathering tool at the end of the year and the researchers obtained each subscale score by adding the responses of the items.

In the lessons a short questionnaire was given that allowed participants to evaluate softwares and to show their expectations. The questionnaires are composed of open-ended questions that ask participants to specify the most important properties that must be in a dynamic geometry software.

\section{Analysis}

Quantitative and qualitative analysis techniques were used to analyze the data. This analysis was made by using descriptive statistics, repeated measures ANOVA and two-way repeated measures ANOVA. The Bonferroni test was used as a post hoc test for comparisons. The data obtained from open-ended questions in the short questionnaire was analyzed by qualitative analysis techniques. Their responses were examined and qualitatively analyzed for the common themes. 


\section{Findings}

\section{Comparison of Softwares}

The descriptive and Analysis of Variance (ANOVA) statistics related to the results of DGSES are summarized in this section. The researchers compared the softwares with respect to the subscales of DGSES.

\section{a. The impact of DGS on students' attitudes and lessons:}

The pre-service teachers evaluated each software according to their impact on students' attitudes and lessons by 6 items. This subscale consisted of items asking subjects to predict the effect of the software on students' attitudes and interests and to rate their preference about the software. Mean scores of "the impact of DGS on students' attitudes and lessons" factor are seen in Table 1.

Table 1. Mean scores of softwares for the impact of DGS on students' attitudes and lessons

\begin{tabular}{lccc}
\hline & Mean & Std. Deviation & Number \\
\cline { 2 - 4 } GeoGebra & 21,5000 & 4,04734 & 64 \\
Sketchpad & 22,6094 & 3,61925 & 64 \\
Cabri 2D & 21,0000 & 4,58431 & 64 \\
\hline
\end{tabular}

Softwares showed statistically significant difference in this factor $(\mathrm{F}(2,126)=$ $6,620, \mathrm{p}=.002<.05)$. After pairwise comparisons were employed by Bonferroni test, it was seen that Geometers' Sketchpad had significantly greater mean scores than GeoGebra and Cabri 2D, while no significant mean difference was found between the GeoGebra and Cabri 2D. Pre-service teachers found Geometers' Sketchpad software more effective in the positive development of the students ' attitudes and lessons than others.

\section{b. High level geometry teaching:}

The pre-service teachers evaluated each software according to their impact on high level geometry teaching by 5 items. This subscale consisted of items asking subjects to rate the benefit of softwares with respect to geometry teaching. It was aimed to explore pre-service teachers' opinions about the effect of three softwares on exploring geometric relationships and demonstrating higher order thinking skills. Mean scores of "high level geometry teaching" factor is seen in Table 3.

Table 2. Mean scores of softwares for high level geometry teaching

\begin{tabular}{lccc}
\hline & Mean & Std. Deviation & N \\
\cline { 2 - 4 } GeoGebra & 16,4000 & 3,04035 & 65 \\
Sketchpad & 17,2615 & 2,97004 & 65 \\
Cabri 2D & 15,9077 & 3,07064 & 65 \\
\hline
\end{tabular}

Their evaluation of softwares gave similar results with the preceding factor. Softwares showed statistically significant difference $(F(1,815,116,145)=8,754$, $\mathrm{p}=.000<.05)$. After pairwise comparisons were employed, it was seen that Geometers' Sketchpad had significantly greater mean scores than GeoGebra and Cabri 2D, while no significant mean difference was found between the GeoGebra and 
Cabri 2D. Pre-service teachers found Geometers' Sketchpad software more effective in teaching high level geometry.

\section{c. Range and ease of use:}

The pre-service teachers evaluated each software according to the "range and ease of use" by 5 items. This subscale consisted of items asking subjects to rate softwares range and ease of use. The ease of use is a characteristic attributable to the process of using a software tool (Gomoll, 1999). The pre-service teachers evaluated the interaction and preparing activities with three softwares according to the range and ease of use issue. Mean scores of this factor are seen in Table 3.

Table 3. Mean scores of softwares for range and ease of use

\begin{tabular}{lccc}
\hline & Mean & Std. Deviation & N \\
\cline { 2 - 4 } GeoGebra & 17,2615 & 3,17843 & 65 \\
Sketchpad & 16,5077 & 2,90002 & 65 \\
Cabri 2D & 15,6769 & 3,06751 & 65 \\
\hline
\end{tabular}

The ANOVA results indicate that there is a statistically significant difference between the mean scores $(\mathrm{F}(2,128)=8,337, \mathrm{p}=.000<.05)$. After pairwise comparisons were employed, it was seen that GeoGebra had significantly greater mean score than Cabri2D $(\mathrm{P}=.000<.05)$, while no significant mean difference was found between the GeoGebra and Geometers' Sketchpad or between Cabri 2D and Geometers' Sketchpad. According to pre-service teachers GeoGebra software is easier than Cabri $2 \mathrm{D}$ to use and has wide area of use.

\section{d. The functionality of Software's in teaching geometric shapes and concepts:}

The pre-service teachers evaluated each software according to their impact on teaching geometric shapes by 3 items. They rated three softwares' functionality about the analysis and the construction of geometric shapes and objects. Mean scores of "teaching geometric shapes and concepts" factor are seen in Table 4.

Table 4. Mean scores of softwares for teaching geometric shapes and concepts

\begin{tabular}{lccc}
\hline & Mean & Std. Deviation & N \\
\cline { 2 - 4 } GeoGebra & 10,9846 & 1,82425 & 65 \\
Sketchpad & 11,0462 & 1,66237 & 65 \\
Cabri 2D & 10,4462 & 2,08440 & 65 \\
\hline
\end{tabular}

Softwares also showed again statistically significant difference $(\mathrm{F}(2,128)=$ $3,638, \mathrm{p}=.029<.05)$. After pairwise comparisons were employed, it was seen that GeoGebra had significantly greater mean score than Cabri2D $(\mathrm{P}=.043<.05)$, while no significant mean difference was found between the GeoGebra and Geometers' Sketchpad or between Cabri 2D and Geometers' Sketchpad. According to pre-service teachers, GeoGebra software has a priority for teaching geometric shapes and concepts. 


\section{Influences of gender and academic achievement to pre-service math teachers' opinions}

The researchers examined the influences of gender and academic achievement by ANOVA statistics. To investigate the effect of academic achievements of preservice teachers, they used the data composed of the course scores. Table 5 illustrates the frequency of the gender variable.

\section{Table 5. Description of Gender Distribution}

\begin{tabular}{ccc}
\hline Gender & Number & Percent (\%) \\
\hline Male & 21 & 31,8 \\
Female & 45 & 68,2 \\
Total & 66 & 100,0 \\
\hline
\end{tabular}

An independent t-test analysis revealed that boys $(\mathrm{M}=52)$ had significantly greater mean scores than girls $(\mathrm{M}=63,1)$ with respect to academic achievement ( $\mathrm{T}=-$ $2,786)$. On the other hand, there is no significant mean difference between boys and girls with respect to factors in the scale. In addition, two-way ANOVA revealed that there was no interaction effect between gender and the factors measured with the pre-service teachers' DGSS scores. The researchers acknowledge that the numbers of pre-service teachers in groups based on gender are not equal and that this is a limitation of this analysis.

Table 6. Descriptive statistics of student achievement levels on the course

\begin{tabular}{cccccc}
\hline & Mean & N & Std. Deviation & Minimum & Maximum \\
\cline { 2 - 6 } High & 76,1364 & 22 & 8,60811 & 67,00 & 100,00 \\
Medium & 60,9318 & 22 & 3,50610 & 55,50 & 66,50 \\
Low & 41,6364 & 22 & 7,99134 & 23,50 & 54,50 \\
Total & 59,5682 & 66 & 15,84028 & 23,50 & 100,00 \\
\hline
\end{tabular}

Table 6 illustrates the data regarding the achievement of all students on the course about mathematics education softwares. There were 66 valid course scores in the data set. They were collapsed into three categories. Researchers obtained equal number of three categories by seperating them into three levels: high $(\mathrm{n}=22 ; 67<\mathrm{X}$ $<100)$, medum(n=22; 55,5 $\leq \mathrm{X} \leq 66,5)$ and low $(\mathrm{n}=22 ; 23,5 \leq \mathrm{X} \leq 54,5)$. ANOVA was used to conduct the analyses for analysing the effect of academic achievement variable. The probabilities of $\mathrm{F}$ test for all of the factors were bigger than alpha level $(\alpha=.05)$. Like gender, there was no interaction effect between achievement groups and opinions of pre-service teachers.

\section{The results of the short questionnaires}

The pre-service teachers' specified the most important properties that they expect from dynamic geometry software by a short questionnaire. They answered the question "What is the most important property of a dynamic geometry software must have?" according to three main categories: Language of the software, visuality of the software, guidance for users. In addition, they were asked to determine the most important property of a software and the most important purpose of its use. Researchers categorized their answers by qualitative techniques and found their 
frequencies. Since there were too many categories elicited from students' answers, the researchers preferred to give only first five categories for every question which represent most part of categories.

Table 6 . What is the most important property of a dynamic geometry software according to the language?

\begin{tabular}{ll}
\hline First Five Categories & Percent (\%) \\
\hline 1. It should be in users' native language & 55,1 \\
2. Appropriate language for curriculum & 19,2 \\
3. Common language all around the world & 9 \\
4. A good translation & 5,1 \\
5. It should be clear and understandable & 5,1 \\
\hline
\end{tabular}

Table 7. What is the most important property of a dynamic geometry software according to the visuality?

\begin{tabular}{ll}
\hline First Five Categories & Percent (\%) \\
\hline 1.Screen clarity and readability & 28,2 \\
2.The use of display area & 19,7 \\
3.Accordance of colours and visual integrity & 15,5 \\
4.I nteresting and attractive image & 12,7 \\
5.Alive colours should be used & 8,5 \\
\hline
\end{tabular}

Table 8. What is the most important property of a dynamic geometry software according to its guidance for users?

\begin{tabular}{ll}
\hline First Five Categories & Percent (\%) \\
\hline A detailed user manual & 24,3 \\
Detailed explanation of its' use in the help menu & 24,3 \\
The number of examples given to the users & 17,1 \\
It should be clear and understandable & 7,1 \\
it should be accessible and helpful & 5,7 \\
\hline
\end{tabular}

Table 9. What is the most important property of a dynamic geometry software?

\begin{tabular}{ll}
\hline First Five Categories & Percent (\%) \\
\hline The ease of use & 35,3 \\
It should have many additional tools like spreadsheets and & 17,6 \\
computer algebra system. & 16,5 \\
It should keep users' computers running fast & 12,9 \\
The ability to calculate and draw & 5,9 \\
It should be appropriate for geometry and proof
\end{tabular}


Table 10. What is the most important purpose of use?

\begin{tabular}{ll}
\hline First Five Categories & Percent (\%) \\
\hline To present subject matter in the lesson & 38,9 \\
To give students some materials that they can study at home & 16,7 \\
To make applications and to reinforce & 13,9 \\
To learn geometry alone (self study) & 12,5 \\
To facilitate the learning process & 5,6 \\
\hline
\end{tabular}

Generally, being in users' native language, the screen clarity and readability and detailed user manual or help menu are most important properties for the pre-service teachers. But the researchers acknowledge that some of these properties are directly related with the competencies of computers. So the software suit to computer competencies are more preferable. The three softwares can be different according to their technologic development, but findings indicated that the pre-service teachers prefer more clear and understandable softwares. One of the statements the preservice teachers used is on the following;

"We can compare them according to their design and technologic development, but the clearest and most understandable is Sketchpad..."

As can be seen from tables 9 and 10, the most important property of a DGS is the ease of use for the pre-service teachers and they prefer DGS to make presentations in the lessons, so they want to use these softwares in the lessons. The second most important property of a DGS is also interesting, additional tools like spreadsheets and Computer Algebra Systems. The researchers think that this property shows the approval of pre-service teachers about the additional tools of GeoGebra.

\section{Conclusion and Discussion}

In this study the researchers focused on three $2 \mathrm{D}$ dynamic geometry softwares and the results revealed that there are not big differences between them according to the pre-service teachers. But they think that Geometers' Sketchpad is more effective than others in the positive development of the students' attitudes and geometry teaching. They also emphasized the potential benefits of GeoGebra, which they prefer it according to "the range and ease of use" factor. The pre-service teachers are looking for more pedagogical and usable softwares. DGS gives students many ways to approach a problem and come up with a logical, evidence based conclusion (Hull \& Brovey, 2004). The pre-service teachers participated this study also emphasized the drag mode or dynamic property of shapes in the softwares. The visualization of concrete geometry concepts is very important for the pre-service teachers, and they believe that attractive image will reinforce the teaching process.

Teachers who are not hesitant to use technology and embrace new teaching methods are more likely to incorporate these methods into their routine than teachers who initially experience difficulties (Mously et al., 2003). These initial difficulties may be language, lack of guidance, lack of computer literacy etc. The researchers assert that it will be possible to benefit from DGS and other softwares more effectively, if we obtain more perfect combinations of technology, pedagogy and mathematics. Even though the advantage of technology in education is widely accepted, the ability to flawlessly incorporate technology is not very easy. The pre- 
service teachers want to integrate this technology into mathematics classrooms by presenting subjects and giving students some activities reinforce their understanding. However, choosing the best software and manipulating the development of well-known softwares are the responsibilities of educators. It is essential that we find ways of using this technology effectively, in the learning environments, as a tool (Allison, 1995).

\section{References}

Allison, L. (1995). The status of computer technology in classrooms using the integrated thematic instructional model. International Journal of Instructional Media, 22(1), 33 - 43.

Bielefeld, T.G. (2002). On dynamic geometry software in the regular classroom. Zentralblattfür Didaktikder Mathematik, 34(3), 85-92.

Daher, W. (2009). Pre-service Teachers' Perceptions of Applets for Solving Mathematical Problems: Need, Difficulties and Functions. Educational Technology \& Society, 12 (4), 383-395.

Erbas, A. K. \& Yenmez, A. A. (2011).The effect of inquiry-based explorations in a dynamic geometry environment on sixth grade students' achievements in polygons. Computers $\mathcal{E}^{\circ}$ Education, 57(4), 2462-2475.http://dx.doi.org/10.1016/j.compedu.2011.07.002

Gomoll, M. (1999). Choosing Contingency Planning Software. The Ease-Of-Use Issue in Software Selection. Disaster Recovery Journal. Vol. 5, 4.

Göktaş, Y, Küçük, S., Aydemir, M., Telli, E., Arpacık, Ö., Yıldırım \& G., Reisoğlu, İ. (2012). Educational Technology Research Trends in Turkey: A Content Analysis of the 20002009 Decade. Educational Sciences: Theory \& Practice - 12(1), 191-196, Educational Consultancy and Research Center

Guven, B. (2012).Using dynamic geometry software to improve eight grade students' understanding of transformation geometry. Australian Journal of Educational Technology, 28(2), 364-382

Hull, A. N., \& Brovey, A. J. (2004).The impact of the use of dynamic geometry software on student achievement and attitudes towards mathematics. Action Research Exchange, 3(1), 24-37.

Hohenwarter, M. \& Fuchs, K. (2004). Combination of dynamic geometry, algebra and calculus in the software system GeoGebra. ZDM classification: R 20, U 70, Retrieved on 10-November-2014,

URL: http://archive.geogebra.org/static/publications/pecs_2004.pdf

Hohenwarter, M., \& Lavicza, Z. (2007). Mathematics teacher development with ICT: towards an International GeoGebra Institute. In D. Küchemann (Ed.), Proceedings of the British Society for Research into Learning Mathematics. 27(3):49-54. University of Northampton, UK: BSRLM.

Kortenkamp, U., \& Dohrmann, C. (2010). User interface design for dynamic geometry software. Acta Didactica Napocensia, 3(2), 59-66.

Isiksal, M. \& Askar, P. (2005): The effect of spreadsheet and dynamic geometry software on the achievement and self-efficacy of 7 th-grade students. Educational Research, 47:3, 333350

Mackrell, K. (2011a). Design decisions in interactive geometry software. ZDM Mathematics Education, 43:373-387 DOI 10.1007/s11858-011-0327-4

Mackrell, K. (2011b). Finding the area of a circle: Affordances and design issues with different IGS programs. Proceedings of the Second North American GeoGebra Conference: Where 
Mathematics, Education and Technology Meet? University of Toronto, Toronto, ON June 17-18, 2011.

Oldknow, A. (2001). Special group 2: DGS - Dynamic Geometry Software. In M. Borovcnik $\mathcal{E}^{2}$ H. Kautschitsch (Ed.): Electronic Proceedings of the Fifth International Conference on Technology in Mathematics Teaching. August, 6-9, 2001 - University of Klagenfurt, Austria.http://wwwg.uniklu.ac.at/stochastik.schule/ICTMT_5/ICTMT_5_CD/Spec ial\%20groups/CD_Special2.htm\#b9

Oldknow, A. \& Tetlow, L. (2008). Using dynamic geometry software to encourage 3D visualisation and modelling. Electronic Journal of Mathematics and Technology.1933-2823 Volume: 2 Source Issue: 1

Petrovici, A. \& Sava, A.T. (2010).CABRI 3D-the instrument to make the didactic approach more efficient. Anale. Seria Informatica. Vol 8, 2.

Roberts, D.L. \& Stephens, L.J. (1999).The effect of the frequency of usage of computer software in high school geometry. The Journal of Computers in Mathematics and Science Teaching, 18(1), 23-30.

Sträßer, R. (2002). Research on Dynamic Geometry Software (DGS) - an introduction ZDM, Vol. 34 (3).

Stols, G. \& Kriek, J.(2011). Why don't all maths teachers use dynamic geometry software in their classrooms? Australasian Journal of Educational Technology, 27(1), 137-151.

Weigand, H.-G. \& Weth, T. (2002). Computer im Mathematikunterricht: Neue Wegezualten Zielen. Spektrum, AkademischerVerlag, Heidelberg, Berlin. 